\title{
«НЕУДОБНЫЙ КЛАСС» В РОССИЙСКОЙ И СОВЕТСКОЙ ИМПЕРИЯХ: ПЕРСПЕКТИВЫ АГРАРНЫХ ИССЛЕДОВАНИЙ В ПОЛЕ ОТЕЧЕСТВЕННОЙ ИСТОРИИ
}

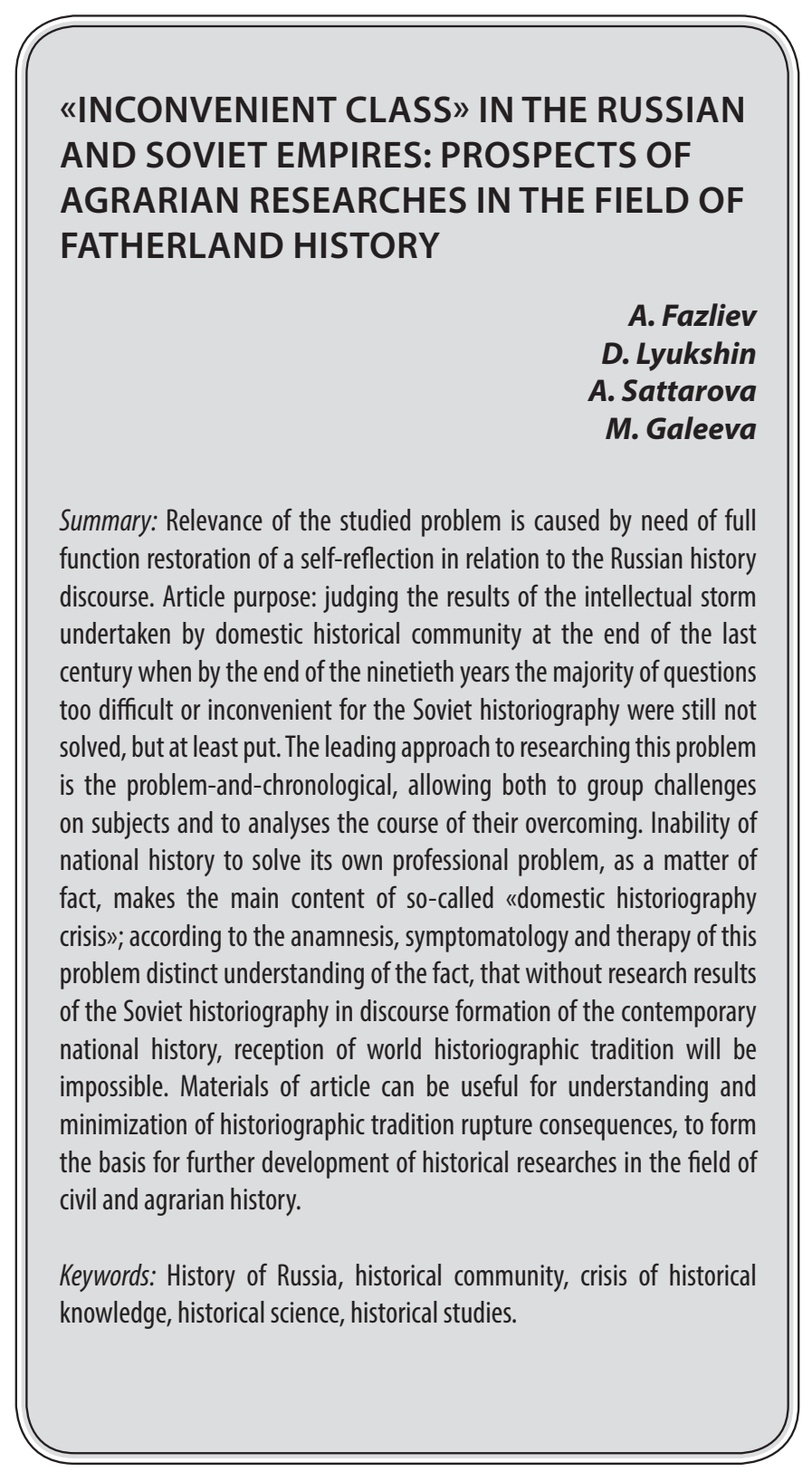

Историческое сообщество в конце девяностых, поднявшееся на штурм бастионов истины, ныне в беспорядке отступает, ссылаясь на очередной кризис исторического знания. К счастью, то, что виделось, как последний бой оказалось банальной кабацкой потасовкой, как по результатам, так и по набору аргументов и мобилизуемых лингвистических конструкций. А, «к счастью», потому что историкам всё ещё удаётся сохранять некое единство корпоративного духа и способность, а главное
Фазлиев Айваз Миннегосманович К.и.н., дочент, Казанский (Приволжский) федеральный университет aivazik@mail.ru

Люкиин Дмитрий Иванович К.и.н., дочент, Казанский (Приволжский) федеральный университет dmitryi.lyukshin@kpfu.ru

Саттарова Аделя Ильхамовна К.и.н., старший преподаватель, Казанский (Приволжский) федеральный университет satadel@inbox.ru

Галеева Марьям Арслановна К.и.н., дочент, Казанский (Приволжский) федеральный университет galeeva_mariyam@mail.ru

Аннотация: Актуальность исследуемой проблемы обусловлена необходимостью восстановления в полном объёме функции саморефлексии, применительно к дискурсу российской истории. Цель статьи: осмысление результатов интеллектуального штурма, предпринятого отечественным историческим сообществом в конце прошлого века, когда к концу девяностых годов большинство вопросов, слишком сложных или неудобных для советской историографии были, если и не окончательно решены, то, во всяком случае, поставлены. Ведущим подходом к исследованию данной проблемы является проблемно-хронологический, позволяющий как сгруппировать вызовы по темам, так и проанализировать ход их преодоления. Неспособность отечественной истории решить собственную профессиональную задачу, собственно говоря, и составляет основное содержание т.н. кризиса отечественной историографии; по анамнезу, симптоматике и терапии этой проблемы должно предшествовать внятное осознание того, что без учёта исследовательских результатов советской историографии в дискурсивной формации новейшей отечественной истории, рецепция мировой историографической традиции окажется невозможной. Материалы статьи могут быть полезными для осознания и минимизации последствий разрыва историографической традиции отечественной истории.

Ключевые слова: история России, историческое сообщество, кризис исторического знания, историческая наука, исторические исследования.

- вкус к анализу сделанного и получившегося.

Наличие рефлексии относительно содержания и результатов познавательного процесса имманентно присущей здоровому исследовательскому сообществу внушает - по крайней мере - сдержанный оптимизм относительно состояния и перспектив развития отечественной исторической науки [2;3;5;10]. Однако очевидная дисфункция в деле поиска новых смыслов - несколько настораживает. Непрерывный синтез означающих, 
исходным материалом для которого выступают сами же означающие, составляя основное содержание процесса, так называемого научного поиска в социальных дисциплинах, обусловливает мутацию образа истины в гуманитарной исследовательской традиции. Эффект мерцающей семантики - врождённый дефект и одновременно способ существования дискурсивной формации наук об обществе - когда означающее скользит над означаемым (в соответствии с Соссюровским алгоритмом S/s) не коррелируя с ним, время от времени инспирирует генерацию исследовательским сообществом серии образов, которые, будучи наброшены на ткань социального более или менее удачно презентируют содержание общественных трендов и даже предоставляют шанс рассмотреть сочетание воли и процессов: между текущими массами означающего и означаемого возникают «тонкие, подобные струям дождя, вертикальные пунктирные линии», оказывающиеся «слишком хрупкими в этом двойном потоке» [8]. Однако и этого довольно, чтобы позволить социологам или философам выгибать формат дискурса под свои концепты, втискивая в одинаковые лингвистические формы иногда совершенно разное содержание. И при этом поддерживать иллюзию, что они не просто понимают друг друга, но и говорят об одном и том же. В прорицании о прошлом, претендующем на роль квинтэссенции гуманитарного знания, шум дождя слышится сегодня, пожалуй, наиболее отчётливо, напоминая, что дискретность является атрибутом дискурсивной формации исторической науки, которой закрыт доступ к Ultima ratio спасительного эксперимента.

\section{Истоки и слеАствия Аефицита инструментов исторического познания.}

Культурный шок и нищету методологии, опосредованную организационно-идеологической сегрегацией советского периода, можно было с полным основанием числить по списку детских болезней новейшей российской историографии, когда бы не наследственность, отягощённая укоренением в качестве атрибутов отечественного исторического знания этацентристского подхода и, - скажем так, - дедуктивной хронологии, в пределах которой любой исторический сюжет мнится эманацией державного тела. Строго говоря, традиция эта родом даже и не из СССР, она возникла непосредственно в процессе формирования дискурса русской истории, квинтэссенцию которого составляла апология государства российского. Более того, ребячливая державность - необходимый этап становления зрелой историографической традиции: своего рода пубертатный период собирающегося под знамёнами национально-государственной историографии сообщества юных друзей Клио. Беда в том, что у нас он несколько затянулся, а обрюзгшие в своих синекурах Мальчиши-кибальчиши, выехав на деревянных лошадках закономерностей прямо из шестидесятых, всё продолжают размахивать картонными мечами в нумерологических дискуссиях, имеющих к постижению заявленного объекта такое же отношение как «поллюция к деторождению» [9]. Зрелище, прямо скажем, «на любителя», хотя, пожалуй, единственная проблема, связанная с использованием дедуктивного метода в качестве профессионального инструмента отечественной истории, в том, что поднимающиеся из «низов» интеракции с его помощью «не берутся», оставаясь вне исследовательского поля. Принимая во внимание весьма умеренную политическую активность населения нашей страны, это затруднение можно игнорировать, однако некоторые события в прошлом Отечества, всё же требуют для истолкования методов, так сказать, индуктивных. Не случайно русская смута XVII века неизменно оставалась наиболее сложным сюжетом для русских историков, а непротиворечивое разъяснение её внутренней логики предполагало некоторую методологическую раскованность. Возникшая на исходе прошлого века задача осмысления Второй русской смуты - с лёгкой руки В.П. Булдакова [4] поименованной «Красной» - также потребовала мобилизации методологических практик, выходящих за пределы традиционной номенклатуры приёмов отечественной историографии.

\section{Методологический переворот поневоле.}

Решительная трансформация социума не оставила представителям русской исторической науки шанса описать события Семнадцатого года, а для обществоведения советского извода методологический плюрализм был немыслим. Впрочем, советские цеховики, подвизавшиеся на ниве прорицания о прошлом, нашли два способа обойти это затруднение. Первый - предполагал подравнивание событий прошлого под тяжёлый ритм законов исторического развития (в итоге Октябрьский переворот Семнадцатого года, например, предстал в качестве закономерного явления, что - попутно - освобождало любознательных исследователей от необходимости углубляться в детали политических технологий большевиков), второй - интерпретацию социально-политических трендов, воплощённых в стихийных массовых движениях, как реакции социального тулова на интеракцию власти или политической группы (в результате появилась возможность настаивать на ведущей роли большевиков в революции 1905 года, например, или, скажем, определить конец 1917-го года как период «триумфального шествия советской власти»), претендовавший на статус актора исторического процесса. Решение для страны с минимально эффективной экспрессивной функцией права весьма смелое, однако же, в дискурсе советского истмата приемлемое. Но вот сбережение этого концептуального комплекса в арсенале современной историографии обусловливает сохранение угрозы непредсказуемости со стороны прошлого. 
Впрочем, отказом от истматовского наследства ограничиться уже и не удастся: осваивая «короткие», а в отечественном исполнении - ещё и мизерные - гранты, движимое стремлением к популяризации и публичной самопрезентации историческое сообщество в начале нынешнего века усвоило себе стиль фастансеринга (от англ. fast - быстрый и answers - ответы), позволяющий быстро фабриковать односложные ответы на вопросы, обращаемые к прошлому. Отличительной особенностью этой методологической новеллы становится безразличие к исследовательской традиции и неограниченная редукция, позволяющая бесконечно рекомбинировать проплывающие по волнам означающего смыслы, более или менее осмысленно симулируя некие подобия концептов, сгущающиеся по мере актуализации темы и развеивающиеся после смещения тренда. Сложилась уже целая генерация учёных, которые просто не имеют представления о природе исторического исследования, ограничиваясь компиляциями в рамках годичных грантов.

Начав со второй половины девяностых годов прошлого века переосмысление ключевых сюжетов отечественной истории, сообщество историков к началу века нынешнего естественным путём пришло к осознанию необходимости рекомбинации символической структуры дискурса. Однако эта проблема, к которой стянуты и высокая наука, и школьная пропедевтика, до сих пор остаётся открытой. Тому есть объективные объяснения: научно-историческая традиция, размытая за годы советской власти, пока история подвизалась на поприще служанки идеологии, не может пока что в полной мере удовлетворить запросы сообщества на генерацию актуальных тем; отмеченный родовым клеймом этацентризма дискурс отечественной истории с трудом акцептует новеллы, в которых отсутствует «руководящая и направляющая» субстанция...

Но заглавной причиной, необходимым условием реализации кризисного сценария в деятельности исторического сообщества является, похоже, потеря историческим сообществом способности к идентификации прошлого нашей Родины с имеющимся в распоряжении обществознания набором шаблонов социально-политического строя. Эдакое патологическое неузнавание, блокирующее как возможность с помощью легального инструментария исторического познания нарисовать непротиворечивую картину прошлого, так и (что намного тяжелее) - реализацию сообществом познавательной интенции.

В качестве симптома это состояние появляется в конце девяностых годов, когда на смену добросовестным попыткам приспособить для нашего прошлого инстру- ментарий теории тоталитаризма, не пришло ничего. Требовавшие прорыва этацентристского дискурса крестьяноведческие и гражданско-исторические подходы по известным причинам были отвергнуты, но и полноценная рецепция формационного подхода, на фоне глобального банкротства марксистской идеологии, оказалась невозможна. Затянувшаяся саморефлексия, которая уже начинает смахивать на нирвану, обусловливает «гниение» дискурса, не испытывающего бодрящего воздействия критики и благотворного влияния динамики.

Строго говоря, как вслед за «великим Ранке», отмечал почти столетие назад Эрнст Трёльч, кризис в исторических исследованиях невозможен, поскольку архивная работа и поиск новых документов прошлого не прекращаются в любых условиях, но трогательная беспомощность концептуализации при детальной проработке локальных сюжетов, доходит «до-смешного» уже в буквальном смысле: «Деятельность крестьянина в традиционном обществе не нацелена на получение прибыли» [6], - кто же станет спорить - деятельность подавляющего большинства людей во все времена не направлена на получение прибыли, просто потому, что нормальные здоровые люди ищут наслаждений и иногда власти... детей хотят, или - там - баньку поставить. Дело не в том, что крестьянин в своих жизненных стратегиях не ориентировался на получение прибыли, а в том, что рыночная координация хозяйства сама по себе не формирует экономически рационального поведения. Или вот, усмотрев в подноготной сокращения «трудоспособного сельского населения», государственную политику «расселения «неперспективных деревень», автор подчёркивает, что тормозом трансформаций выступали, слаборазвитая инфраструктура села, традиции труда, досуга, быта, культурно-психологический строй деревенской жизни» [7]. Это надо так понимать, что по хорошим дорогам колхозники бежали бы в города ещё быстрее, или речь идёт о каких-то разнонаправленных трансформационных потоках? Причём одному из них явно мешал деревенский modus vivendi. И почему при переходе из второй в третью фазу модернизации и интенсификации аграрного производства «дефицит молочных и мясных продуктов стал постоянным явлением»? И это ещё из лучших!

Эвристический потенциал концепта этики выживания в приложении к российской истории был очевиден два десятка лет назад, очевиден - и сейчас. Проблема в том, что даже в 2011 году всё ещё всерьёз требовалось: «...привести доказательства того, что теоретическая концепция «моральной экономики» крестьянства имеет прямое отношение к положению дел в деревне России в начале прошлого века и внятно объяснить, зачем вообще это требуется доказывать» [1]. 


\section{Историческое сообшество: попытки саморефлексии.}

Сообществу крестьяноведов, ревниво коснеющих в сознании своей «незалежности», тяжело отслеживать актуальные тренды [11], но и в истории, претендующей на мобилизацию инновационных эвристических практик, аналогичная ситуация. Хотя, и здесь всё объяснимо: идеологическая подоплёка исторического нарратива, составляющая нечто вроде скелета исторического самопознания (каким уж оно сложилось на сегодняшний день), в отечественной истории практически невозможна, поскольку любая национальная самопрезентация, апеллирующая к прошлому, содержит некий урок, позитивное содержание которого, собственно говоря, и призвано легитимировать существование той или иной социальной общности.

Вот и отечественная история рефлекторно стремится развернуть ретроспективу прогресса. Правда, после 1917-го и 1991-го рассчитывать на позитивную нотату из прошлого россиянам явно не приходится, хотя бы потому, что тотальное отрицание исторического опыта, - коим отмечены указанные даты, - исключая идею поворота из интерпретации прошлого, обязывает популяризатора, подвизающегося в амплуа прорицателя о прошлом, расставить напротив этих цифр знаки «+» и «-» (причём два одинаковых знака ставить нельзя, и «минус на минус» - плюса не даёт). Задачка, сродни классической апории: «Казнить нельзя помиловать», вот только результат в обоих случаях получится членовредительским. Ну а поскольку отыскать образцы для подражания в прошлом не получается, постольку и поиски исторического смысла бытия Отечества несколько осложняются, вплоть до полного его отрицания в согласии с доктриной постомдерна, - этой французской «болезнью», неосторожно подхваченной группой доверчивых неофитов.

Соответственно, вопрос о вскрытии природы неузнавания пока, во всяком случае, остаётся открытым. Экспертная площадка здесь определяется формирующимся par excellence резюме о патогенном характере этого феномена. И, между прочим, поднимать руку до того, как успеешь додумать ответ - не самый удачный выбор. Пределы саморефлексии исторического сообщества, конечно той его части, которая ещё способна на такую процедуру, ограничиваются двумя крайними вариантами интерпретации синдрома неузнавания: первый, - это симптом тяжкого недуга, поразившего членов исторического цеха; второй, неузнавание - всего лишь очередной лукавый способ выживания сообщества, сродни практикам замещённого познания - Синто, открывающий путь к снятию симптоматики.

\section{Итоги самопознания: Аиагноз или эпикриз.}

Поскольку диагноз в данном случае ставится на основе самообследования, - оно должно быть максимально объективным, что весьма непросто гарантировать - на кону оказывается не просто профессиональное реноме национального исследовательского сообщества, но и перспектива поддержания автономного исследовательского дискурса. Не вполне понятно, куда авторы клонят? Попробуем пояснить. Сразу оговоримся, что каждый из ответов имеет как лестные, так и нелицеприятные аспекты. Начнём с версии симптома, в рамках которой диагностируется усталость деквалифицировавшегося сообщества историков, которое, утратив параметры научной школы, больше не способно исполнять познавательную функцию и формировать знаково-символическую систему образов прошлого. Проще говоря, историческое сообщество не перенесло тягот постсоветского периода и приказало долго жить. Поэтому ближайшая задача сохранившихся в наличии историков - обеспечить, во избежание нарастания энтропии, скорейшую реставрацию дискурса. Такая точка зрения позволяет опереться на развитую традицию русской истории, волшебным образом совместив её с дискурсивной формацией Истории СССР.

Реализация заглавной интенции научного познания, - поиска объективной истины, - предполагает напряжённую и постоянную рефлексию и саморефлексию научного сообщества относительно хода и результатов собственной деятельности. Между тем в отечественной истории разрывы исследовательской традиции препятствуют решению научных задач. Рассогласование дискурсивных формаций русской истории и отечественной истории постновейшего времени исключает не только возможность прямого заимствования исследовательских результатов имперских историков, но и непосредственное продолжение исследований досоветского периода.

Ближайшие перспективы исторического сообщества. По-человечески понятная и выглядевшая вполне логичной попытка избавиться от марксистской методологии, - сполна показавшей свою неэффективность, - обернулась расколом исследовательского сообщества и методологическим кризисом, преодолеет который, удалось лишь вне рациональной сферы, задействовав механизм забывания прошлого, вытеснения его сюжетов за рамки исторической памяти. Результатом этого процесса, продолжающегося в исторических исследования без малого два десятка лет как раз и стала невозможность идентифицировать и описать российский и советский 
социум в границах исторического поля. В этом смысле для российских историков весьма полезным может оказаться опыт постсоветского штурма, предпринятого отечественным историческим сообществом, когда к концу девяностых годов большинство вопросов, слишком сложных или неудобных для советской историографии были, если и не окончательно решены, то - во всяком случае - поставлены. Однако разрыв исследовательской традиции не позволил большинству российских истори- ков адекватно воспринять результаты дискуссий, развернувшихся в исследовательских центрах на закате XX века. В результате, отечественной историческое сообщество вынуждено вновь осваивать уже пройденные темы. И хотя мы можем утешаться мыслью о том, что это естественный процесс, требующий определённого времени, именно его дефицит во многом определяет отставание гуманитарного сектора российской науки от современных исследовательских трендов.

\section{ЛИТЕРАТУРА}

1. Бабашкин В.В. Концепция «моральной экономики» крестьянства и российская деревня начала XX века // Крестьяноведение: теория, история, современность. 2011., Вып. 6. С. 135-156.

2. Бордюгов Г.А., Бухараев В.М. Вчерашнее завтра: как «национальные истории» писались в СССР и как пишутся теперь. М.: АИРО-ХХІ, 2011. 247 с.

3. Бордюгов Г.А., Ушаков, А.И. «Поиски альтернативных структур в исторической науке. М.: АИРО-ХХ, 1998. 143 с.

4. Булдаков В.П. Красная смута. Природа и последствия революционного насилия. М.: РОССПЭН, 1997. 376 с.

5. Вашик К. Представление исторического знания и новые мультимедийные технологии. М.: АИРО-ХХ, 1999. 128 с.

6. Есиков С.А., Есикова М.М. Традиции и новации в аграрной культуре России (1880-1917 гг.)» // Крестьяноведение. Теория. История. Современность. 2011, Вып. 6. С. 157-175.

7. К Корнилов Г.Е. Модернизация аграрной сферы России в XX веке: региональное измерение // Крестьяноведение. Теория. История. Современность. 2011, Вып. 6. С. 210-228.

8. Лакан Ж. Инстанция буквы в бессознательном или судьба разума после Фрейда / [пер. с фр. А.К. Черноглазова, М.А. Титовой]. Москва: Русское феноменологическое 0-в0, 1997. 183 с.

9. Ленин В.И. Материализм и эмпириокритицизм (1909). URL: http://www.magister.msk.ru/library/lenin/len14v02.htm (провер. 24.5.2020).

10. Поляков Ю.А. Наше непредсказуемое прошлое. Полемические заметки. М.: АИРО-ХХ, 1995. 216 с.

11. Скотт Дж. Благими намерениями государства. М.: Университетская книга, 2005.568 с.

(c) Фазлиев Айваз Миннегосманович (aivazik@mail.ru), Люкшин Дмитрий Иванович (dmitryi.lyukshin@kpfu.ru),

Саттарова Аделя Ильхамовна (satadel@inbox.ru), Галеева Марьям Арслановна (galeeva_mariyam@mail.ru).

Журнал «Современная наука: актуальные проблемы теории и практики» 